\section{Bourbaki's Structures and Structuralism}

The Mathematical Intelligencer encourages comments

about the material in this issue. Letters to the editor

should be sent to either of the editors-in-chief, Chandler

Davis or Marjorie Senechal.

have read with interest Osmo Pekonen's review of Amir Aczel's book, The Artist and the Mathematician, in The Mathematical Intelligencer, Vol. 31 (2009), No. 3. I had already read the book and had been surprised again and again by Aczel's complete freedom with historical facts (see, for example, his comparison of André Weil, born in 1906, with Alexander Grothendieck, born in 1928).

But here I will concentrate on just one important point: The supposed relation of Bourbaki's structures to structuralism. This is a pure intellectual fraud, propagated by many people from the social sciences and repeated by Aczel. Bourbaki's structures and structuralism had independent births, even if we wave hands and refer to the Zeitgeist.
But let us be precise.

The idea of structure appeared in mathematics before Bourbaki in the theory of abstract algebra of commutative fields (E. Steinitz, "Algebraische Theorie der Körper," Jour. für die reine und angewandte Mathematik 137 (1910), 167309), in linear algebra, and also in the beginning of the theory of continuous groups with Elie Cartan. Bourbaki was directly inspired by them (Pierre Cartier, personal communication, April 2010).

The word "structure" appeared independently in Claude Levi-Strauss's book Anthropologie Structurale (1958). When structuralism became a fashion in the 1960s, referring to Bourbaki in structuralist essays was a way of giving some scientific credit and weight to works of variable quality.

When I asked Claude Levi-Strauss about the origin of the word "structure" in his work, he answered (letter to the author, Nov. 16, 1990): "Ne croyez pas un instant que Bourbaki m'ait emprunté le terme "structure" ou le contraire, il me vient de la linguistique et plus précisément de l'Ecole de Prague." (Do not believe for one minute that Bourbaki borrowed the word "structure" from me, or the contrary; it came to me from linguistics, more precisely, from the School of Prague.)

This, I hope, puts an end to any discussion about the origin of "structures."

Jean-Michel Kantor

Institut de Mathématiques de Jussieu

4, Place Jussieu,

Case 247-

75005 Paris, France

e-mail: kantorjeanm@gmail.com 